\title{
LA TRANSFOMACIÓN DEL PAISAJE URBANO DE SANTANDER DESDE EL GRABADO DE JORGE BRAUN DE 1575 A LA GREACIÓN DEL GENTRO GULTURAL BOTÍN EN 2017
}

\section{THE URBAN LANDSCAPE TRANSFORMATION OF SANTANDER FROM THE 1575 JORGE BRAUN'S ENGRAVING TO THE GREATION OF THE BOTIN GULTURAL GENTER IN 2017}

\author{
MARÍA JESÚS POZAS POZAS \\ Profesora Senior. Doctora en Historia \\ Facultad de Ciencias Sociales y Humanas. \\ Universidad de DEUSTO -Bilbao \\ Apartado 1. 48080 BILBAO (España) \\ TIfn: + 34943326440 \\ Email: mpozas@deusto.es
}

PALABRAS CLAVES

Paisaje, urbanismo, Santander, ciudad, Jorge Braun, Centro Botín.
KEY WORDS

Landscape, urbanism, Santander, city, Jorge Braun, Center Botin. 


\section{Resumen}

Se analiza la evolución del paisaje urbano de la ciudad marítima de Santander situada en el Norte de España desde el S. XVI a la actualidad. Partimos de diferentes imágenes socio-espaciales, sin olvidar la relación entre mentalidades colectivas, ideologías e historia urbana, para lo cual hemos aplicado una metodología interdisciplinar.

La primera imagen conocida de Santander se debe al grabado de Jorge Braun de 1575, al que se le atribuye un valor simbólico del espacio urbano, para terminar con los cambios paisajísticos de la última remodelación urbana a propósito de la edificación del Centro Cultural Botín en 2017, que ha generado un profundo cambio en la imagen de la ciudad y de su bahía, coincidiendo con el modelo de la adaptación de las ciudades a la globalización económica, para convertirse en un escaparate con el fin de atraer visitantes.

Pero las grandes transformaciones se llevaron a cabo en los siglos XIX y XX impulsadas por la burguesía y la aristocracia al conjuro de las estancias estivales del Rey Alfonso XIII (1912-1930) en Santander, para convertirse en una ciudad elegante y cosmopolita. Por otra parte, el gran incendio de 1941 arrasó el casco antiguo, y cambió el paisaje urbano para siempre, de sus cenizas renació una ciudad nueva construida según la tipología de la arquitectura franquista. En la segunda mitad del S. XX debido a la inmigración, al turismo de masas y a la especulación se dibujó un nuevo mapa urbano.

\section{Abstract}

It is analyses the evolution of the urban landscape of the Santander maritime city, located in the North of Spain from the 16th century to the present day. We start from different sociospatial images, without forgetting the relationship between collective mentalities ideologies and urban history, for which we have applied an interdisciplinary methodology.

The first image known of Santander is the Jorge Braun's engraving of 1575, which is attributed a symbolic value of urban space, to finish with the landscape changes from the latest urban renewal concerning the construction of the Cultural Center Botin in 2017, that has generated a profound change in the image of the city and its bay, coinciding with the model of adapting the cities to economic globalization, to become a showcase to attract visitors.

But the great transformations were carried out in the 19th and 20th centuries by the bourgeoisie and the aristocracy as a consequence of the summer stays of King Alfonso XIII (1912-1930) in Santander, to become an elegant and cosmopolitan city. On the other hand, the great fire of 1941 razed the old town, and forever changed the urban landscape, from its ashes was reborn a new city built according to the typology of the Franco's architecture. In the second half of the 20th century due to immigration, tourism of mass and the speculation was drawn a new city map. 


\title{
Introducción
}

\author{
Cristal feliz de mi niñez, \\ mi clásica y romántica bahía, \\ consuelo de hermosura y geografía, \\ bella entre bellas del harem de España". \\ (Gerardo Diego:1941).
}

La finalidad de este trabajo consiste en analizar desde fines del siglo XVI hasta 2017 la evolución del paisaje urbano de la ciudad marítima de Santander situada en el Norte de España en la costa cantábrica, y capital de la Comunidad Autónoma de Cantabria. Para encuadrar este tema partimos de una de las ideas más conocidas del filósofo José Ortega y Gasset que decía: "Yo soy mi circunstancia” (Ortega y Gasset, 2014).

¿Pero qué se entiende por el término circunstancia?. La circunstancia es el mundo vital en que cada uno nos hallamos inmersos y hace referencia a la familia, a la cultura, a la sociedad y al momento histórico; además se incluye el cuerpo y la mente de la propia persona, nos vamos formando con el encuentro del mundo en que vivimos, y el mundo forma parte de la realidad que cada uno percibe, el de las personas, las cosas y el de nuestra circunstancia, y al hacerse cargo de uno mismo incluimos el entorno; al mismo tiempo enfocamos nuestros proyectos de vida; de ahí la importancia del microcosmos de la ciudad y del paisaje como elemento espiritual y transformador de la existencia.

El paisaje urbano ha marcado la historia de la ciudad de Santander, y la de sus habitantes, de modo que a través de su estudio podemos aportar unas conclusiones que sirvan de base para un conocimiento más ajustado de la "Historia de la ciudad", dentro de un panorama historiográfico aún insuficientemente investigado en estos aspectos, y que al mismo tiempo nos sirva de reflexión para evitar futuras agresiones al medioambiente, y al paisaje que es el mayor patrimonio que posee la ciudad de Santander, y desgraciadamente se ha venido deteriorando su calidad en las últimas décadas, debido a la irresponsabilidad de los políticos, a la especulación, y a la pasividad de una sociedad clasista, pero sobre todo mayoritariamente conformista como es la sociedad santanderina, lo cual nos inclina a pensar en la baja valoración que le concede a los paisajes auténticos que le han dado carácter a la ciudad, y que están estropeando.

Sabemos que el ciudadano observa para captar cualidades especiales de un lugar para ubicarse físicamente, y determina cuales son los aspectos más importantes de una ciudad, y como van variando. En el caso por ejemplo de Santander, el ciudadano ve como la construcción de nuevos edificios al borde de la bahía influyen en la imagen que recibe, y requiere de la exploración y el ensamblaje mental para situarse así mismo, ya que es importante que los edificios conecten con el paisaje, y por otro lado éstos tienen que unir el cariño que los ciudadanos sienten por la ciudad, pues el paisaje evoca recuerdos, sentimientos y emociones.

La estructura de este trabajo se basa en diferentes imágenes socio-espaciales, y como han sido percibidas éstas por los hombres y mujeres de otros tiempos; y por otra parte, como ven el paisaje los actuales habitantes, para lo cual aplicaremos la tesis que proponía Marc Bloch cuando afirmaba que "para comprender 
el presente hay que conocer el pasado" (Bloch, 1980: 34-41). En cuanto a la metodología, utilizaremos un método multidisciplinar como requiere este tipo de investigaciones.

La imagen que tenemos hoy del paisaje urbano de Santander no se parece en nada a la primera imagen conocida de la ciudad gracias al grabador alemán Hoefnagel, y que Jorge Braun incluiría en 1575 en su obra "Civitatis Orbis Terrarum", a este grabado se le atribuye un valor simbólico, y actualmente se ha convertido en una "imagen icónica" de la ciudad. Sin embargo, a partir de esta vista captamos los cambios que se han producido a lo largo de más de cuatrocientos años, siendo el punto de partida para intentar reconstruir la realidad histórica de los hombres y mujeres que han vivido en Santander en la larga duración. Asimismo, la historia, como ciencia de los seres humanos en el tiempo, tiene la necesidad de unir el estudio de los muertos con los vivos, puesto que la historia siempre la hacemos desde el presente. Además, los habitantes de una ciudad a través del tiempo acumulan un depósito de imágenes visuales que van variando a lo largo de la vida, pues el paisaje de una ciudad es dinámico y no estático (Cullen, 1974); porque según Lucien Febvre "vivir es cambiar" (Febvre, 1975:59).

Concluiremos esta investigación con el análisis de los cambios paisajísticos de la última remodelación urbana de Santander a propósito de la construcción del Centro Cultural Botín inaugurado en junio de 2017, y que ha generado un profundo impacto en la imagen de la ciudad y de la bahía, teniendo en cuenta que ésta ha sido clasificada en 2016 como una de las más bonitas del mundo por el "Club de las Bahías más Bellas del Mundo". La construcción del Centro Cultural Botín coincide con el modelo de la adaptación de las ciudades a la globalización económica, con el objetivo de convertirse en un escaparate para atraer a visitantes dentro del fenómeno del turismo de masas; pero existen otros intereses como por ejemplo los de la poderosa familia Botín dueños del Banco de Santander, que en parte ha financiado el museo.

Pero para entender la relación entre el paisaje urbano, la ciudad y los ciudadanos hay que penetrar en la historia de la ciudad, y en el caso de Santander se puede afirmar que participa hoy de los avatares que afectan a la fachada cantábrica; según el último censo de población de 2016 cuenta con 172.656 habitantes (INE, 2016). Si comparamos este censo con el de 1991 que proporcionaba la cifra de 196.218, se desprende que ha perdido un total de 23.562 habitantes en los últimos 25 años, y ha retrocedido a las cifras de población de finales de los años setenta del siglo pasado, esto significa que cuando un territorio pierde población de forma continuada está ocurriendo algo serio; parece que este indicador no preocupa a las autoridades municipales, que minimizan estas cifras cuando deberían de adoptar medidas para no dejar languidecer la ciudad con los problemas, y riesgos que esto implica, pues entre otras causas el descenso de la población se debe a que los jóvenes se marchan de la ciudad, y esto supone, que Santander se va a convertir en un futuro próximo en una ciudad envejecida, y por último hipotecará su futuro, y si todo esto fuera poco está perdiendo lo más valioso que tiene que es el patrimonio paisajístico (Zubieta, 2015).

Santander es una ciudad nueva nacida de las cenizas del trágico incendio que prácticamente la arrasó en 1941, en aquellas cenizas quedó la vieja ciudad con sus calles y edificios, pero la que se ha construido en el mismo lugar tiene que ver con ella, y así hoy podemos recomponer sus calles y hogares, porque como 
decía el arquitecto Fernando Chueca Goitia "aunque una ciudad desapareciera por completo arrasada hasta no quedar ni la ceniza de sus hogares, la que se construyera en el propio lugar tendría que ver siempre con ella" (Chueca, 1968: 31-32; 1975). No hay que olvidar que toda ciudad es por sí misma un formidable archivo de recuerdos, y si no conocemos históricamente a la ciudad, tampoco podremos conocer a sus habitantes, porque la ciudad es un ser histórico.

\section{Objetivos}

Los principales objetivos de este trabajo consisten en realizar una síntesis analítica de la evolución del paisaje urbano de la ciudad de Santander desde 1575 a 2017. Nos centramos en el análisis de los cambios que se han producido en el desarrollo urbano, y como estos han modificado el paisaje a lo largo del arco temporal elegido para esta investigación, para lo cual hemos empleado las herramientas teóricas y metodológicas, que nos han permitido aproximarnos con la mayor objetividad posible a este tema. Por otra parte, ahondamos en las imágenes como fuente del ideario colectivo, y de la memoria histórica, con el fin de reflexionar sobre las últimas actuaciones urbanas llevadas a cabo en Santander, como ha sido la construcción del Centro Botín en el frente de la Bahía, que ha despertado el interés de los agentes de la sociedad civil por el impacto del urbanismo en el paisaje.

\section{Metodología}

El desarrollo de la metodología atiende a tres estrategias situadas en la larga duración, y que en conjunto abordan un proyecto desde una perspectiva global: 1) La primera imagen de Santander según el grabado de Jorge Braun de 1575. 2) Los cambios urbanísticos desde el Antiguo Régimen a la Contemporaneidad, y 3) La última remodelación urbana de 2017: El Centro Cultural Botín.

La metodología aplicada se fundamenta en la interdisciplinariedad para correlacionar los datos, y llevarnos a reflexionar sobre el pasado y el presente de la ciudad de Santander. Para la obtención de los datos hemos utilizado fuentes tradicionales: documentos, bibliografía y prensa; además de fuentes obtenidas de Internet como: entrevistas, encuestas, información judicial, valoraciones personales, y material fotográfico.

Todo este utillaje nos ha posibilitado estructurar y articular las diferentes fases del trabajo para llegar a unas conclusiones diáfanas.

\section{Primera imagen de Santander según el grabado de Jorge Braun en 1575}

La ciudad de Santander debe su razón de ser a los imperativos físicos y a las actuaciones de las personas que han dominado la naturaleza, y a las técnicas creadoras de la producción y del comercio; evidentemente, no se puede despreciar la acción genética de un puerto natural como es el caso del de Santander para el nacimiento de la ciudad; sin embargo, el comercio fue el principal motor de su crecimiento (VV. AA, 1985). 
En el siglo XVI se transformó en el principal puerto exportador de las lanas castellanas hacia el noroeste de Europa; fue también el puerto preferido de las armadas reales; precisamente en 1570 por orden de Felipe II se convirtió en la Base Naval del Cantábrico donde Ilegaban las Armadas reales (Pozas, 2014: 553-567). El puerto de Santander constituyó un lugar privilegiado, donde afluían los hombres atraídos por las aguas, por lo que su imagen e historia aparecerá junto a una serie de ciudades importantes europeas del siglo XVI. La primera imagen que tenemos de Santander se trata del grabado de Franz Hogenberg sobre el dibujo base del artista flamenco Georges Hoefnagel arcediano de Dormund que estuvo en Santander en 1575 y realizó el dibujo de la villa tantas veces reproducido, que sería publicado por Jorge Braun decano de la colegial de Colonia, que recorrió diversas ciudades europeas para tomar vistas lo más fielmente posible, tanto de las ciudades como de su entorno, y anotaba todas aquellas cosas que le parecían de interés. El grabado titulado "Santander" fue publicado por Jorge Braun en su magna obra "Civitates Orbis Terrarum", impresa entre 1572 y 1617 en seis volúmenes reeditados varias veces. El dibujo correspondiente a Santander aparece en el volumen II. La versión original del grabado era en blanco y negro, más tarde se editaron ejemplares coloreados a mano, y se reprodujo éste a doble página con un relato en latín facilitado por los propios santanderinos. ${ }^{1}$

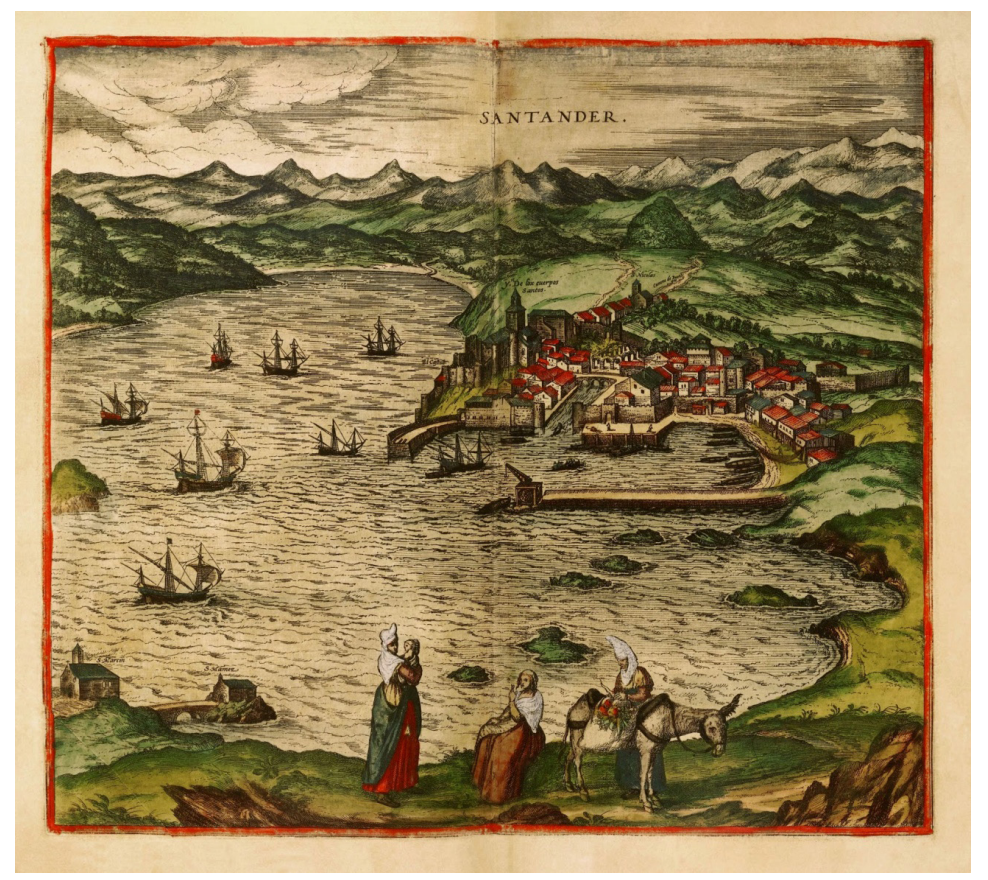

Figura 1. Vista General de Santander. Grabado de Jorge Braun y Frans Hogenberg (1575). Fuente: https://escenasdesantander.blogspot.com

En el grabado puede verse una representación panorámica de la bahía con una serie de naos, la Abadía de los Cuerpos Santos y el castillo en la Puebla Vieja, que se unía a la Puebla Nueva por un puente sobre la ría de Becedo: además se observa el edificio arruinado de las Atarazanas Reales, a la derecha del muelle se destaca la "machina" para carga y descarga de embarcaciones, con el tiempo los santanderinos la llamarían "grúa", otro elemento era la muralla, y el camino de Burgos que partía de la Puebla Vieja, al fondo la cordillera Cantábrica, y la peña de Peñacastillo; en un primer plano se pueden observar tres mujeres vestidas con trajes de la época, dos de las mujeres estaban casadas y una soltera, se sabe por los tocados que llevan en la cabeza, las "capiruchas" o tocados de mucha altura con formas fálicas se remontan a los 
tiempos anteriores al cristianismo, y por su paganismo fueron prohibidos por la iglesia, las sayas eran largas hasta los tobillos, y el calzado cerrado (Hoyos, 1978-1979: 251-257). ${ }^{2}$ El grabado ofrece numerosos detalles de la historia de la Villa, razón por la cual es un documento de sumo valor para aproximarnos al paisaje urbano de Santander de finales del siglo XVI. (Escudero, 2005; 2017).

\section{Los cambios urbanísticos desde el Antiguo Régimen a la Contemporaneidad}

El espacio urbano que ocupaba Santander durante el Antiguo Régimen, no sufrió variaciones significativas, si exceptuamos la expansión que afectó a la ciudad en las últimas décadas del siglo XVIII, y a la ampliación del puerto gracias al crecimiento del comercio. Por otra parte, entre finales del siglo XVI y principios del siglo XVII se sitúa el hundimiento del puerto de Santander, lo que dio lugar a una etapa de contracción que abarcó todo el seiscientos, y la terrible peste de 1596, fue el comienzo de una inversión de las tendencias. Estos derrumbes económicos y demográficos, incidieron en las mentalidades colectivas y en el urbanismo (Echevarría, 1995).

En este contexto de crisis generalizada se registraron algunos periodos de recuperación, pero no se llegó a alcanzar ni de lejos las cifras de población anteriores a la peste de 1596. Los efectos de la depresión se prolongaron hasta mediados del siglo XVIII. Antes de la gran peste la población de Santander se cifraba en unas tres mil personas, era una micro-ciudad, característica de las ciudades del Norte de España, cuando se extinguió la peste en 1597, se evaluaron las pérdidas humanas en casi dos mil personas.(Pozas, 1973).

En el siglo XVII el comercio se paralizó con en Noroeste de Europa debido a las guerras con Holanda, Inglaterra y Francia, los muelles se arruinaron, desapareció el comercio, y se produjo un proceso de ruralización (Elliott, 1982: 198-223). Sobre el paisaje y el urbanismo de Santander en la segunda mitad del seiscientos contamos con el testimonio del canónigo suizo Pellegrino Zuyer, quien, en 1660 visitó la ciudad para informar a Roma sobre la misma, y su insistente pretensión de erigirse en Obispado independiente del Arzobispado de Burgos (Lodos, 1942: 395-439).

El canónigo suizo dejó un plano esquemático de la ciudad y sus alrededores con una serie de observaciones en las que describía la ciudad con sus calles, y callejuelas, el puerto, el malecón, las murallas, los torreones que defendían la entrada del puerto antiguo, la rampa de la grúa, casi sin variaciones a como lo dibujó Hogenberg en la obra de Jorge Braun en 1575 (Simón Cabarga, 1979: 12).

Las viviendas constituían el núcleo básico del paisaje urbano y los materiales empleados eran preferentemente vivos, como la madera y la piedra. El canónigo Zuyer describió las casas de Santander como "muy ordinarias, la mitad de piedra y la otra mitad de madera. "No he visto más de seis o siete casas que tuvieran proporciones de verdaderas casas y todas de piedra; en particular, la del Veedor, frontera a la iglesia de los padres jesuitas en la cabeza de la plaza”. (Simón Cabarga, 1979: 13-14). A principios del siglo XVII se construyó el complejo religioso y educativo de los jesuitas en el centro de Santander junto al Ayuntamiento, y 
a otros edificios nobles de carácter civil, como puede apreciarse al noreste de la plaza en el plano de Zuyer. Fue la única transformación urbana de la ciudad en esta centuria, actualmente sólo queda la iglesia llamada de la Compañía (Pozas, 2017:13-31).

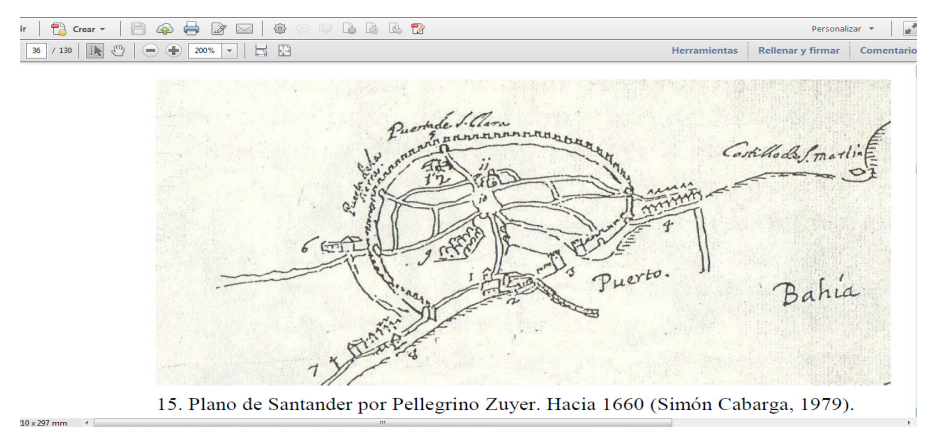

Figura 2. Plano de Santander por el canónigo suizo Pellegrino Zuyer hacia 1660 Fuente: Simón Cabarga, José. (1979). Santander. Biografía de una ciudad. Santander. Ediciones de Librería Estudio, p. 32.

A principios del siglo XVIII, Santander se nos muestra como una ciudad medieval encorsetada por las murallas, pero a lo largo del setecientos se pueden señalar claramente dos etapas urbanas bien definidas. La primera comprende desde principios de siglo hasta 1754, fecha de la erección del obispado, y 1755 en que se le concedió el título de ciudad por Fernando VI, en esta época ya existía una preocupación por el urbanismo; la segunda se extiende hasta finales del siglo, coincidiendo con las transformaciones urbanas y la expansión de la ciudad debido a un importante desarrollo económico y demográfico, gracias al aumento del comercio y de la inmigración (Rio y Saínz, 1889: T. Il: 574-575).

Es evidente que las medidas políticas de los Borbones influyeron positivamente en el desarrollo económico de Santander, junto con los beneficios del comercio, la apertura del camino de Reinosa en 1753 que enlazaba la meseta castellana con el puerto para la exportación de lanas y cereales, y la incipiente industrialización operaron un constante crecimiento urbano (Palacio Atard, 1960). La estructura cerrada del espacio ciudadano producto de la herencia medieval, se transformó bajo la inspiración de las nuevas ideas ilustradas; una primera medida consistió en derribar las murallas que no tenían ya una finalidad defensiva. Se urbanizaron nuevas zonas al Este de la ciudad sobre terrenos ganados al mar, y se sentaron las bases del urbanismo de los siglos XIX y XX; se puede afirmar que el Santander moderno nació a finales del siglo XVIII.

Al conjuro de estos cambios surgió una nueva burguesía que a tenor de las nuevas teorías sociales y económicas, pensaba en el urbanismo como en una fuente más de riqueza; sin embargo, es necesario mencionar dos tipos de urbanismo: uno respondía a los intereses políticos de la Administración del despotismo ilustrado (edificios públicos, la Aduana, el Consulado, el Hospital de San Rafael, y los muelles), y otro a los intereses particulares de la burguesía, que veían en los bienes inmuebles un modo de enriquecimiento y un signo de prestigio social (De Vries, 1987). Santander, con sus dos ciudades bien diferenciadas, (la ciudad vieja, y la ciudad nueva), aceleró su desarrollo a partir de 1780 con la proliferación de construcciones, y acabó de modernizarse para su época a través de experiencias nuevas, tanto políticas como sociales y económicas; 
su sociedad tenía una indudable originalidad y una mentalidad nueva, en definitiva estaba destinada a un porvenir brillante en la Edad Contemporánea. (Pozas, 1999: 216 -373).

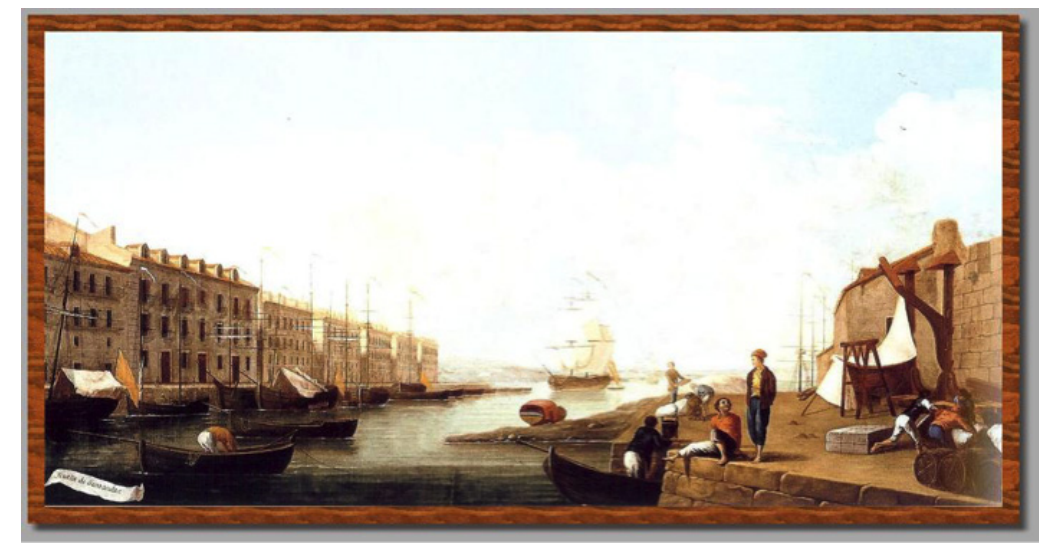

Figura 3. El muelle de Santander en 1794. Cuadro de Mariano Sánchez Fuente: https://www.sbhac.net

A finales del siglo XVIII surgió una nueva mentalidad burguesa, racional, ilustrada y moderna, que va a marcar las diferencias con las clases populares; se dedicó a especular con los terrenos ganados al mar, que fueron una de sus fuentes de riqueza, y mantuvo la idea ilustrada del urbanismo como simetría y perfección. Todas las casas eran iguales como elemento de identidad del grupo, el ejemplo más representativo son las cinco primeras manzanas del muelle que serán continuadas en el siglo XIX.

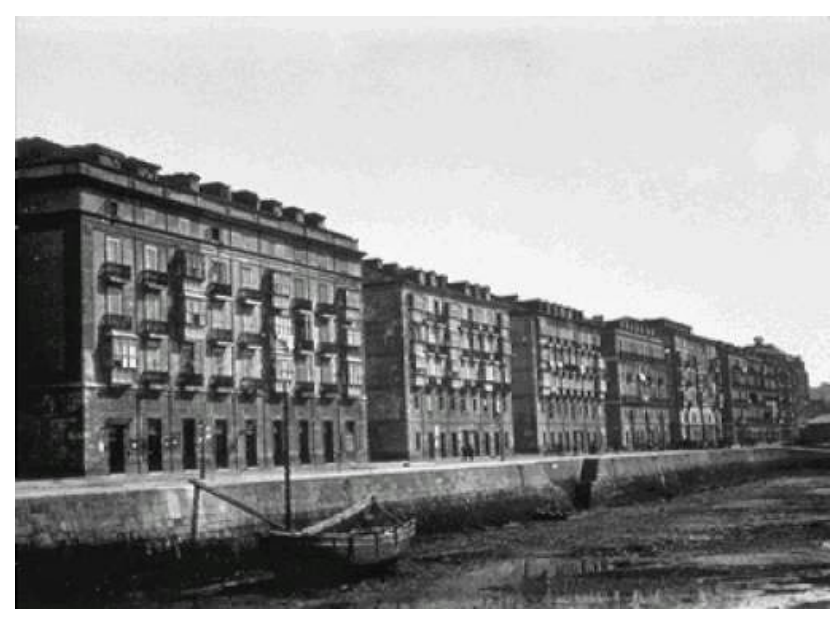

Figura 4. El muelle de Santander en 1881

Fuente: https://escenasdesantander.blogspot.com

El urbanismo de Santander en el siglo XIX pasó por varias etapas, y se puede afirmar que se construyó una ciudad nueva mirando al mar, que ocultó la vieja ciudad destartalado como ocurre en la actualidad. A partir de 1850 Santander conoció una importante vitalidad económica y social de la burguesía local, y un considerable crecimiento demográfico. Se continuó con el ensanche de la ciudad por el Este, pero al mismo tiempo se proyectó otro llamado de Maliaño al Oeste de la bahía, que no se desarrolló por dos factores principales: el trazado del ferrocarril hasta el puerto en el eje urbano, y la destrucción de gran parte del ensanche de Maliaño por la explosión del vapor “Cabo Machichaco" en 1893 que además ocasionó cerca de 600 muertos y más de 2000 heridos; en consecuencia se abandonó el proyecto del ensanche por el 
Oeste por la cercanía del puerto, hasta que se volvió a retomar en la década de los años cuarenta del siglo XX.(Sazatornil, 1996: 38).

Gracias al crecimiento del tráfico harinero procedente de Castilla, y a la exportación de minerales se impulsó el urbanismo, se abrieron nuevas calles, se construyeron plazas y mercados, estaciones ferroviarias, y se rellenó el antiguo puerto, y grandes superficies de la bahía que cambiaría la línea de costa de la ciudad; en cambio apenas se intervino en el centro histórico, y todos los esfuerzos se volcaron en la creación de una larga línea de muelles continuos, y de un barrio nuevo al Este de la ciudad (Rodríguez, 1987).

Con la pérdida de las últimas colonias en 1898 el comercio de las harinas se hundió, y se reorientó el urbanismo hacia la revalorización del casco antiguo donde estaban los centros de poder, de modo que nació una nueva idea de ciudad, y la centralidad urbana ya no sería el puerto.

No obstante, en 1900 el puerto constituía la seña de identidad de Santander, y como ciudad portuaria experimentó un notable dinamismo comercial e industrial, entre 1886 y 1904 el 95\% de las empresas registradas en la actual Cantabria tenían su sede en Santander, y como consecuencia del crecimiento económico se produjo un considerable aumento demográfico, que generó un alto grado de urbanización, y un cambio significativo en las tipologías arquitectónicas, y en la transformación del paisaje (Ortega, 1998: 13-55, y Lanza, 2005: 117-160).

En cuanto a la evolución urbana del siglo XX hay que destacar otros dos periodos: el primero hasta el gran incendio de 1941, y el segundo corresponde a la reconstrucción de la ciudad, y al mayor proceso de una urbanización "depredadora" que se produjo a partir de los años cincuenta (Ordeig, y Valtierra, https://dadun. unav.edu>bitstream>Urb).

A principios de siglo la ciudad siguió extendiéndose hacia el Este, se construyó la dársena de Puertochico, y se perfiló la calle Castelar con bellos edificios residenciales que iba a enlazar con el Paseo de Reina Victoria en el camino del Sardinero, un paraje de singular belleza transformado en "ciudad balneario" a finales del siglo XIX, y potenciado por las estancias veraniegas de la reina Isabel II, y del rey Amadeo de Saboya.

Pero fue la construcción de un palacio en la península de la Magdalena en 1912, regalo de la ciudad de Santander al Rey Alfonso XIII, donde la familia real pasaría las temporadas estivales hasta 1930, la razón por la cual se promocionaría definitivamente el Sardinero, convirtiéndose en uno de los espacios más elegantes de la costa cantábrica, se construyeron magníficos edificios siguiendo el paradigma de la arquitectura de la "Belle Époque" como el Gran Casino del Sardinero (1916 )y el Hotel Real (1917), y en la misma época se edificaron hermosas casas y hoteles para la aristocracia y la burguesía que acudía a Santander atraída por la corte veraniega, y por la belleza de sus playas. Actualmente bastantes edificios han desaparecido para construir viviendas multifamiliares de una arquitectura comercial fruto de la voraz especulación, por lo que el paisaje ha perdido en gran parte la belleza y el encanto de otros tiempos. 


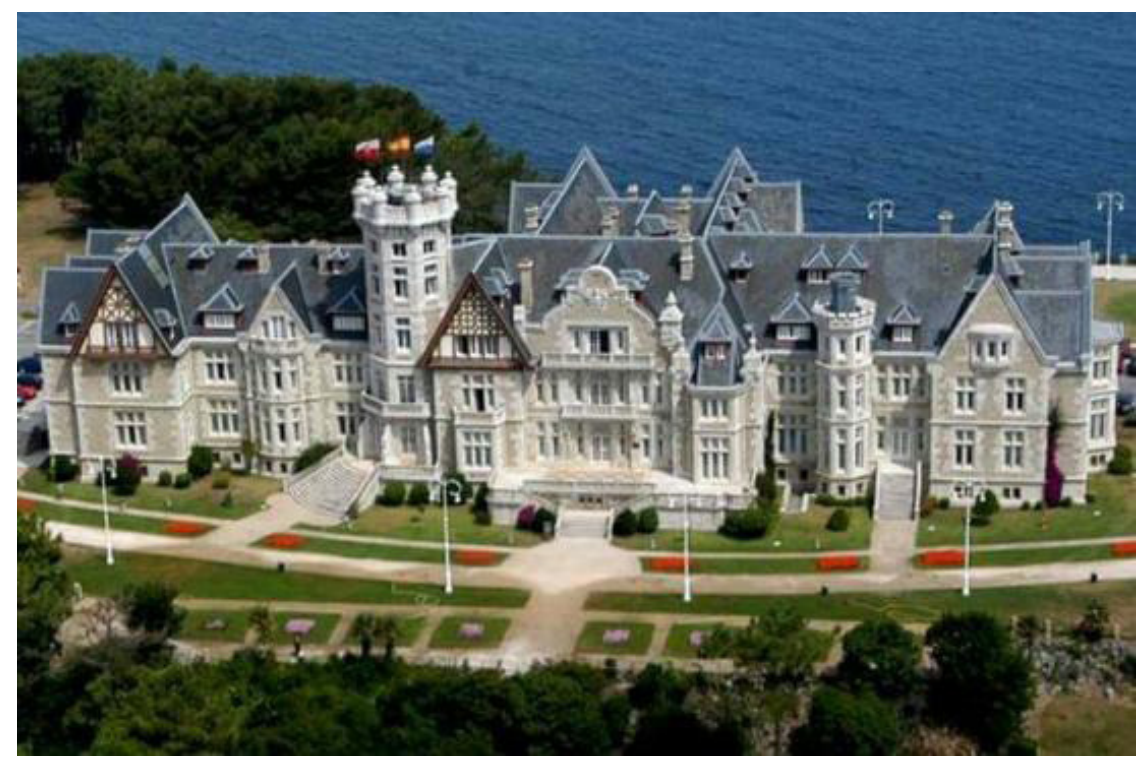

Figura 5. Palacio de la Magdalena de Santander de estilo "inglés" Fuente: https://palaciomagdalena.com/es/historia/

Volviendo al incendio de 1941 que arrasó el casco antiguo de la ciudad, desaparecieron numerosos edificios y otros quedaron muy dañados como la catedral, la iglesia de la Compañía, el Ayuntamiento, palacios, y la mayor parte del comercio que se concentraba en el centro. En su reconstrucción se impuso la arquitectura franquista de la época, que ha marcado la historia urbana y mental de la ciudad hasta el presente. Por otro lado se desató una extraordinaria especulación, se produjo una nueva reorganización social, y las clases bajas fueron expulsadas a la periferia (Rodríguez, 1980).

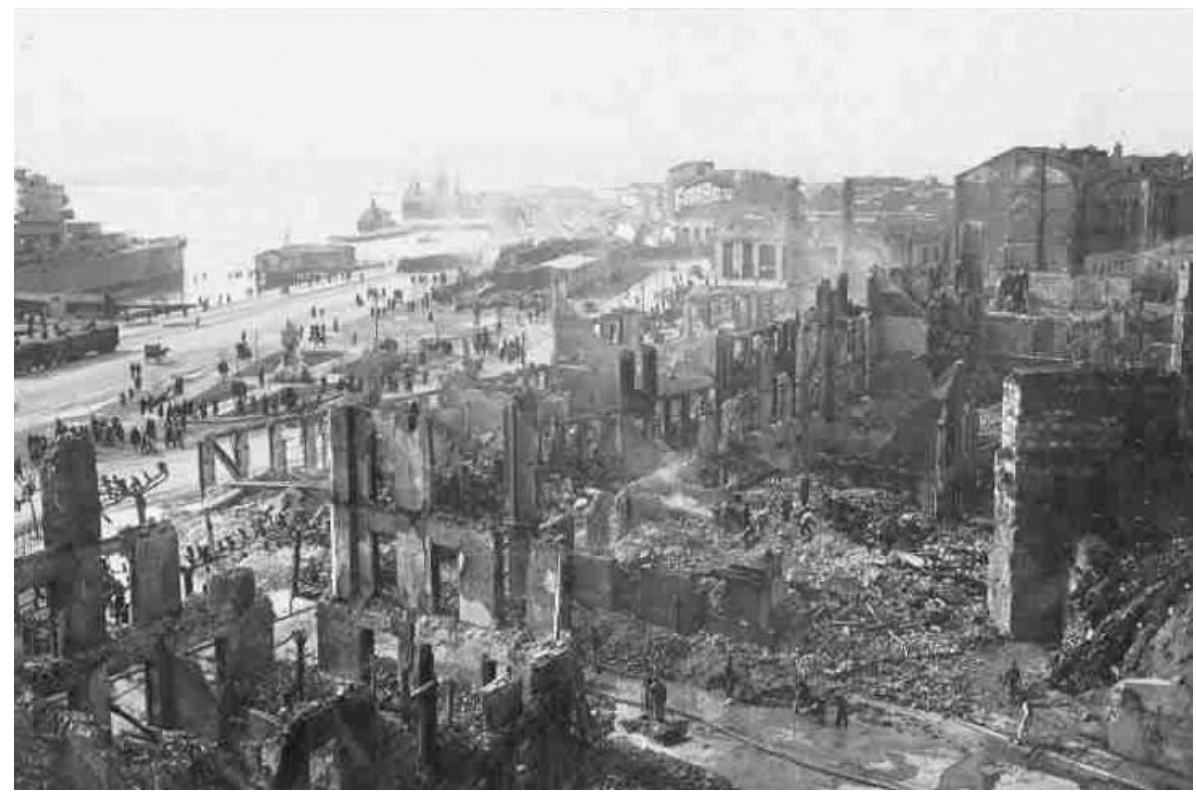

Figura 6. El incendio de Santander en 1941

Fuente: https://www.bing.com/images/search?q=incendio+de+santander+de+1941 
A partir de los años 50 se realzaron las cualidades culturales de la Universidad Internacional de Menéndez Pelayo, y se hizo propaganda de la ciudad como culta y cosmopolita. Sin embargo, en los años 60 y 70 con el desarrollismo económico pasó de ser una ciudad veraniega a un enclave turístico; este cambio sirvió para fomentar los negocios de la construcción inmobiliaria y especular con el paisaje. En estas décadas, Santander conoció un importante crecimiento demográfico, y se llevaron a cabo construcciones masivas de viviendas, faltas de diseño y equipamiento; nos encontramos ante edificaciones en desniveles y cuestas; este es el Santander ignorado pues, lo mismo que en el pasado, la ciudad se emplazó asomándose al sur desde donde se puede contemplar bellos paisajes. Por último, Santander se ve afectada por la recesión económica de las últimas décadas, y se ha dejado llevar por unos planteamientos optimistas desde los gobiernos municipal y regional, sin asumir las situaciones de postergación y retroceso económico y social existentes (Pozas, 1999: X). En 1997 la Comunidad Europea situó a Cantabria como una región problema o una región en declive (Hoyo, 2000: 30-63).

\section{La última remodelación urbana de 2017: El Centro Cultural Botín}

La última remodelación urbana de Santander en 2017 se debe de plantear de forma global a partir de la construcción del edificio del Centro Cultural Botín que ha transformado el paisaje urbano como no se había producido en el pasado con un impacto extraordinariamente agresivo. La obra es del estudio Building Workshop del arquitecto italiano premio Pritzker, Renzo Piano en colaboración con el estudio internacional del español Luis Vidal. Se ubica en la parte central de puerto de Santander, un lugar privilegiado, en la línea del muelle sobre su hermosa bahía, la única de la costa cantábrica que está situada al sur de la ciudad, junto a la icónica "Grúa de Piedra" que comenzó a funcionar en 1900, y al "Palacete del Embarcadero" construido en 1932 de estilo ecléctico, es un edificio emblemático y forma parte del ideario colectivo de los santanderinos, y de los históricos jardines de Pereda que se encuentran en el centro de la ciudad, y ocupan un espacio ganado al mar donde antes estaba el antiguo puerto y sus muelles mercantiles, que veíamos en el Grabado de Jorge Braun.

Los jardines de Pereda se inauguraron en 1905, llevan el nombre del gran escritor montañés José María de Pereda (1833-1905) autor de célebres novelas de costumbres; en el centro de los jardines se levantó un monumento dedicado a este insigne literato.

Los nuevos jardines de Pereda se reinauguraron en 2014 dentro del proyecto del Centro Botín, en esta remodelación los jardines han perdido el encanto de jardín romántico o jardín inglés que tenían, y a pesar de que han ganado en extensión han perdido patrimonio vegetal según el recuento de los árboles existentes antes de la remodelación. Los actuales jardines se integran con el Centro Botín, y ambos están situados en línea recta con el edificio de la sede central del Banco Santander en el Paseo de Pereda, como un signo del poder económico de la familia Botín, y no es casualidad que al sur de la bahía se inaugurara en 2012 un edificio denominado el "Bunker", situado en el pueblo de Solares, al sur de la bahía, y que constituye uno de los grandes centros de procesos de datos (CPDs) del Banco de Santander, que respaldan su red informática 
mundial. En este Centro se han construido dos edificios gemelos que se asemejan a un bunker de ahí el nombre del edificio, con dos torres en forma de prismas que llevan el logo del Banco Santander, que a su vez generan un enorme impacto en el paisaje rural de singular belleza por sus prados verdes y montañas, y desafian a la emblemática Peña de Cabarga, enclavada en el Parque Natural del Macizo del mismo nombre, considerada como el faro de piedra que mira hacia la bahía de Santander; casualmente el Bunker y las torres están enlazadas con esa línea imaginaria del poder, que une la sede central del Banco Santander, el Centro Botín y el Bunker . ${ }^{3}$

El proyecto del Centro Botín fue promovido por la Fundación Botín creada en 1964 y presidida desde 1993 por el anterior presidente del Banco de Santander Emilio Botín (1934-2014), que presidió el Banco Santander desde 1986 hasta su muerte en 2014, y le convirtió en líder del sector bancario español; en 2012 fue nombrado el mejor banco del mundo por "Euromoney". El proyecto del Centro Cultural de Emilio Botín se basaba en tres aspectos: "debía de ser social, a través de la creatividad y el arte. También aspiraba a tener un impacto global como foro de atracción; pero, además tenía el compromiso de potenciar lo local de Santander y Cantabria, protagonistas del cambio que supone este Centro en el conjunto de España" (Pulido, www.abc. es y González, www. Eldiariomontanes.es).

El objetivo de Emilio Botín era más que construir un edificio crear un nuevo espacio cívico que generase una actividad continúa a través del arte y de la cultura, pero en este proyecto, el más importante de la Fundación Botín, no se ha tenido en cuenta el impacto paisajístico y emocional que supone a los santanderinos a pesar de que se adorne de metáforas poco afortunadas y cursis, se le define como un edificio que se asemeja a "una pequeña nave espacial a punto de tocar tierra", "el edificio corteja al mar". "un barco más en la Bahía", un edificio "recubierto de piel de cerámica blanca y reflectante", "el Centro Botín se convertirá en un faro que espera conducir a Santander hacia una nueva dimensión". Lo que es una realidad, que en ningún caso se ha pretendido que sea un edificio "invisible" desde la ciudad, y del lado sur de la bahía, porque por encima de todo significa un claro símbolo de poder de la familia Botín, y al mismo tiempo genera transcendencia a la entidad del Banco de Santander. ${ }^{4}$

El proyecto no ha estado exento de polémicas por la elección del enclave al que se oponían ciertos sectores de la ciudad, entre ellos las asociaciones ecologistas como la Asociación para la Defensa de los Recursos Naturales de Cantabria (ARCA), Ecologistas en Acción, Cantabria Nuestra, y la Asociación para la Conservación de la Arquitectura Tradicional en el Litoral de Cantabria, la Plataforma DEBA (Plataforma en Defensa de la Bahía), y la Plataforma para la Defensa del Sur de Cantabria, que presentaron, alegaciones, denuncias y querellas contra la ubicación del Centro Botín ante el Tribunal Superior de Justicia de Cantabria (TSJC), y en el Tribunal Supremo por "situar un edificio en pleno frente marítimo y en un espacio público de excepcional valor, con la intención de favorecer a un particular, aún a costa de ocasionar un grave perjuicio a la configuración de la ciudad, y al contacto de sus habitantes con el puerto". A estos colectivos se unieron movimientos sociales y vecinales. 
Por una parte, este proyecto rompía las vistas de la bahía hacia la cordillera cantábrica y transformaba radicalmente el paisaje, y por otra era necesario para finalizarlo sortear la legalidad vigente como la Ley de Costas, y el Plan General de Ordenación de Urbanismo (PGOU) de Santander, que sería modificado en 2012 , lo mismo que la Modificación Puntual N 9 del Plan Especial de Ordenación del Sistema Portuario de Santander para dar cobertura legal a un edificio que no cumplía la normativa urbana. En 2016 el Tribunal Supremo anuló el Plan General de Ordenación de Urbanismo (PGOU) de 2012, pero no hubo consecuencias para finalizar las obras del Centro Botín. Tampoco ha sido un proyecto democrático porque desde las Instituciones no se ha dado la palabra a los ciudadanos para expresarse bien a favor o en contra de este proyecto a través de una consulta o referéndum, mientras que han sido las Administraciones, Ayuntamiento de Santander, Autoridad Portuaria, Ente Público Puertos del Estado, Comunidad Autónoma de Cantabria, Ministerio de Fomento, grupos de presión, partidos políticos y los seudo-intelectuales quienes han tomado esta decisión de sacar adelante el Centro Botín, que no sólo compromete de forma multifactorial a las generaciones presentes sino también a las futuras. Precisamente todas las alegaciones y denuncias de los grupos contrarios a este proyecto han sido desestimadas por los tribunales de Justicia españoles, por lo que han llevado sus protestas ante el Tribunal de Justicia de la Unión Europea (De la Peña, eldiariocantabria, 3/05/2017).

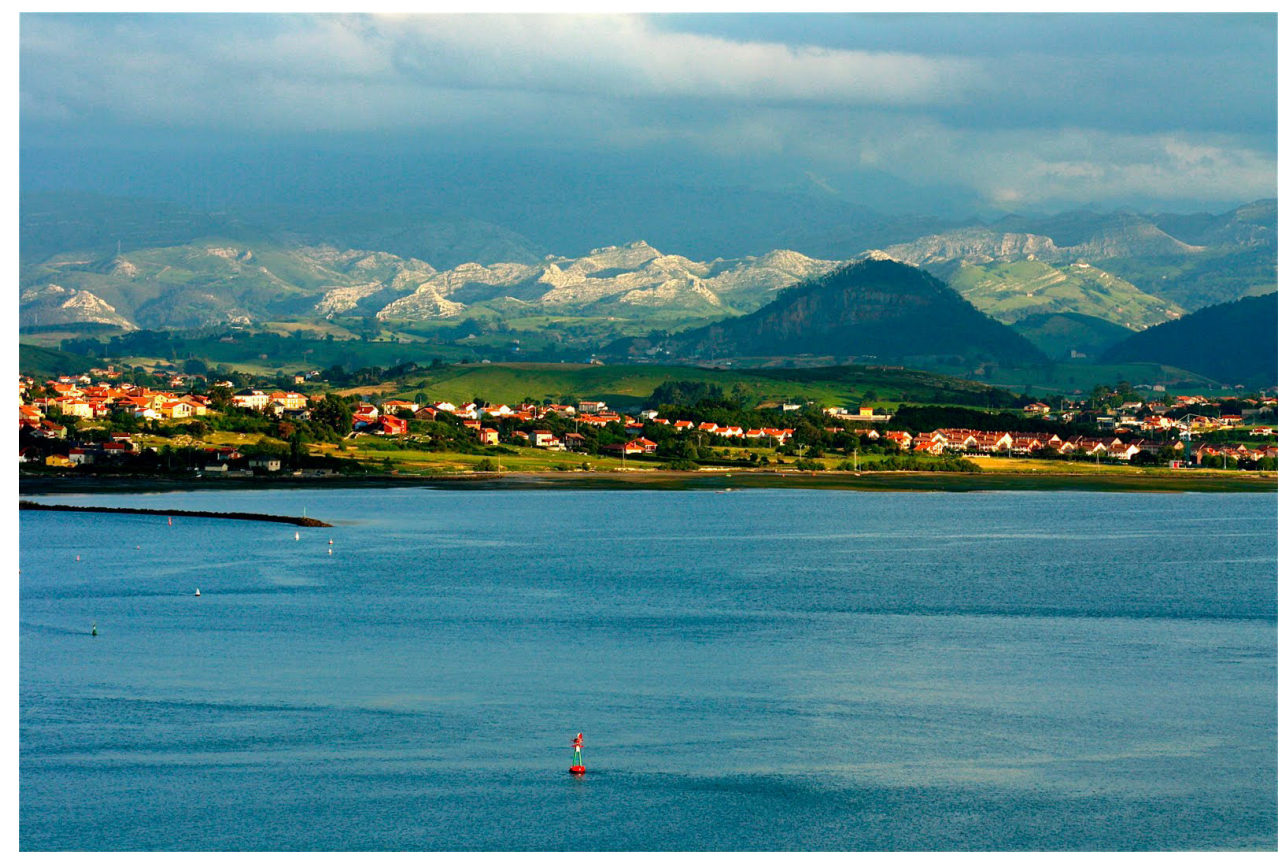

Figura 7. Vistas del paisaje al sur de la bahía de Santander

Fuente: https://elfarodeferia.wordpress.com/2016/10/12/bahia-de-santander/

Otro de los aspectos opacos de Centro Botín es el económico, se dice que ha costado 100 millones de euros y que 80 ha financiado la Fundación Botín, la pregunta es ¿Cómo una ciudad en crisis como es el caso de Santander hará frente a estos gastos extraordinarios? ¿Se recortará todavía más en el gasto social? Ahora se ha abierto una nueva polémica porque los constructores reclaman un sobrecoste de 25 millones a la Fundación Botín. 
El objetivo del Centro Botín pretende rehabilitar la ciudad y situarse en el siglo XXI, buscando "un efecto transformador milagroso como el que consiguió Bilbao con el Guggenheim”. Sin embargo, los milagros no existen salvo para determinadas creencias religiosas, porque tomar como ejemplo a Bilbao es volver a ignorar la historia de cada una de estas dos ciudades, ya el gran estadista Gaspar Melchor de Jovellanos a finales del siglo XVIII visitaba Bilbao y Santander, y sus conclusiones sobre las dos ciudades eran diametralmente opuestas (Pozas, 1992: 107-126).

Hoy día Santander sigue siendo una ciudad portuaria mientras que Bilbao ha trasladado el puerto al exterior de la Ría, Bilbao fue una ciudad industrial y Santander comercial, hoy sumida en una profunda crisis, Bilbao supo renacer de la reconversión industrial de los años ochenta del siglo pasado, y se ha convertido en una ciudad moderna y dinámica, sin renunciar a ese pasado industrial; de modo que las características sociales y urbanas no son comparables, y tampoco lo es el papel que ha desempeñado la burguesía en la transformación de ambas ciudades; mientras que en Santander la burguesía tradicionalmente ha sido de "vuelo corto", la de Bilbao se ha caracterizado por su espíritu emprendedor; por lo tanto es un error que Santander pretenda emular a Bilbao en este caso con la construcción de su "pequeño Guggenheim", pues cada ciudad tiene su propia historia y personalidad. ${ }^{5}$.

No obstante, el gran patrimonio de la ciudad de Santander es el paisaje de la bahía que no han sabido o querido respetar ni las Instituciones ni muchos ciudadanos, mientras que se han ignorados las críticas de quienes no compartían este proyecto, y han permitido destrozar las vistas de la Bahía y de las montañas que la circundan, pero la construcción de un monumento a la familia Botín permanecerá mirando a la Bahía de Santander (Navarro,_Www.publico.es, 07/2017). El emplazamiento del Centro Botín vulnera las condiciones medioambientales y paisajísticas del frontal marítimo portuario de todo el arco SE-SW de la bahía, y no sólo constituye un obstáculo para la navegación de los ferrys que atracan en la cercana Estación Marítima de Santander, sino que ocupa un espacio urbano de alto valor, y fractura la integración puerto-ciudad.

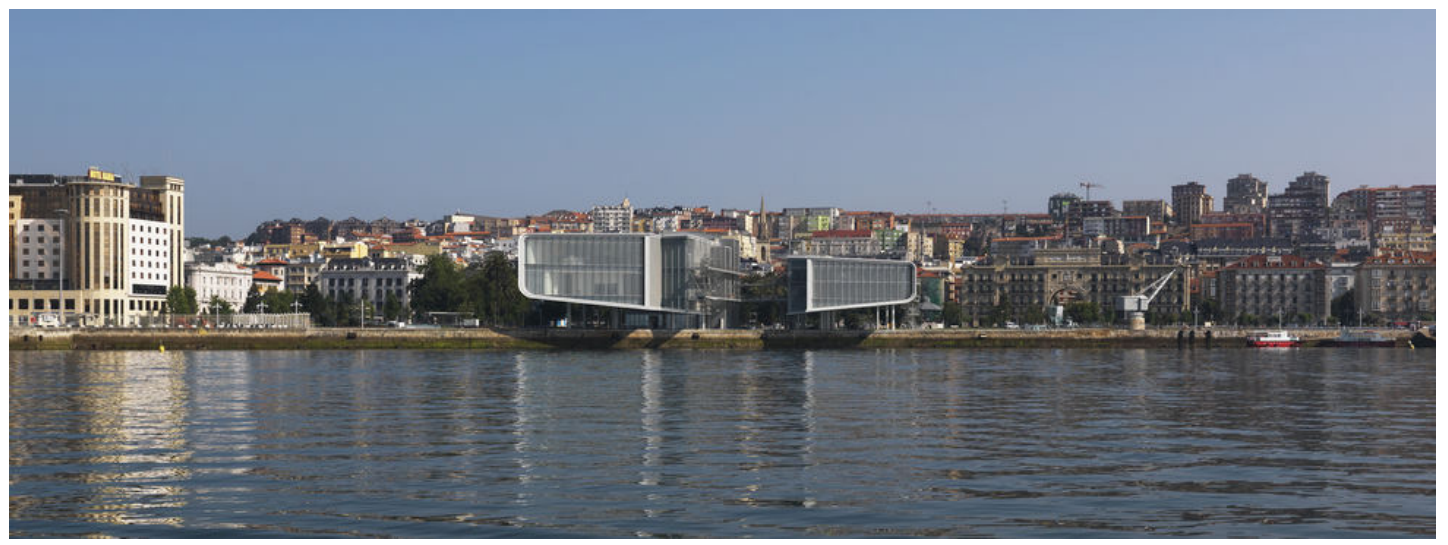

Figura 8. Edificio del Centro Botín formado por dos edificios en el centro del muelle sobre la bahía Fuente: https://www.hola.com/viajes/2017080797964/centro-botin-santander 


\section{Conclusiones}

Santander ha sido una buena representación de la ciudad medieval, de la del Antiguo Régimen, y de la ciudad portuaria de los siglos XIX y XX. La economía de Santander ha dependido del puerto, al que debe su forma urbana. La imagen de la ciudad en el grabado de Braun responde al urbanismo medieval, trazado irregular, calles estrechas, y tortuosas callejuelas. La expansión de la "vieja ciudad" a fines del siglo XVIII cambió su estructura general, y la ciudad nueva quedó soldada a la vieja por el Este. En el Antiguo Régimen se convirtió en una ciudad escala entre los campos castellanos y los puertos americanos y del noroeste de Europa.

El comercio fue uno de los principales motores del crecimiento económico, demográfico, de las transformaciones urbanas y del paisaje. También el emplazamiento tuvo sus ventajas, aunque sólo fuera la belleza de su puerto y de la bahía.

Hoy día no se puede entender la historia de Santander sin su relación con el mar a lo largo de su historia, por lo que se falta a la verdad histórica y se ofende a la inteligencia cuando hay quien afirma en la actualidad lo contrario, para justificar la edificación del Centro Botín que aprovecha un trozo de terreno para uso urbano en el muelle de la bahía, porque "Santander ha vivido la mayor parte de su existencia de espaldas al mar". Esta afirmación toma forma de mentira y falsedad en el término jurídico de la palabra, y es un insulto a la verdad, lo que significa ignorar la historia de Santander, pero no basta con darse cuenta del engaño, se deben de descubrir los motivos, y es lo que hemos intentado probar en este trabajo, para demostrar que las mentiras van asociadas a un complejo de vanidad de individuos "mitómanos".

Se pude afirmar sin ningún género de dudas, que existe una relación evidente entre la arquitectura, la política y el poder económico como se puede demostrar después de un análisis sereno en el caso de las últimas transformaciones urbanas de Santander, y hay que desenmascarar la retórica y al mismo tiempo mostrar cómo algunos arquitectos ignoran la configuración del espacio de las ciudades y su historia, basándose en el narcisismo y por encima de todo les interesa dejar una obra propia. En el caso de Renzo Piano la única obra que ha realizado en España es el Centro Botín, y ha seguido fielmente los deseos del patrocinador para reflejar su espíritu en el proyecto, salvo algunas modificaciones que llevó a cabo para eludir las leyes. En definitiva los intereses económicos están al servicio de los proyectos megalómanos de los poderosos, respondiendo a los nuevos valores de la postmodernidad, como la búsqueda de la inmortalidad a través del arte y de la cultura inmaterial con la finalidad de glorificar el poder.

\section{Referencias}

\section{Fuentes manuscritas}

Biblioteca Municipal de Santander Menéndez Pelayo [B.M.P.], Colección Pedraja, Doc. 941, Ms. 6. Varias versiones, autógrafas e inéditas, de don Marcelino Menéndez y Pelayo. (Dentro del volumen, aunque independiente de él hay dos hojas sueltas impresas, en las que se reproduce la Descripción de Santander/por/Jorge Braun/Traducción de Menéndez Pelayo. 


\section{Fuentes impresas}

De Assas, Manuel. (1847). en la serie "España pintoresca". Semanario Pintoresco Español. Incluye el capítulo "Santander".

Río y Saínz, José Antonio. (1889). La provincia de Santander considerada bajo todos sus aspecto. Santander. Imp. De Atlántico. 2 tomos.

\section{Bibliografía}

- $\quad$ Bloch, Marc. (1980). Introducción a la historia. Madrid. F. C. E., $10^{\mathrm{a}}$ ed.

- $\quad$ Chueca Goitia, Fernando. (1968). Breve historia del urbanismo. Madrid. Alianza Editorial.

- $\quad$ Chueca Goitia, Fernando. (1975). Santander, Ciudad y Naturaleza. .Santander. Fundación Marcelino Botín.

- $\quad$ Cullen, Gordon. (1974). El paisaje urbano, tratado de estética urbanística. Barcelona. Blume y Labor.

- De Hoyos, Nieves. (1977-1978). "Tres trajes de mujeres de Santander en el siglo XVI y algo sobre sus tocados". Publicaciones del Instituto de Etnografía y Folklore-Hoyos Sainz, IX, pp. 251-257.

- De la Peña, Maxi. (2017). "El Centro Botín, un exponente de la arquitectura del poder”, en eldiariocantabria, 03 de mayo.

- $\quad$ De Vries, Jan. (1987). La urbanización de Europa 1500-1800. Barcelona. Crítica.

- Diego, Gerardo. (1941). Alondra de Verdad. Madrid. Ediciones Escorial.

- Echevarría, María José. (1995). La actividad comercial del puerto de Santander en el siglo XVII. Santander. Autoridad Portuaria de Santander.

- $\quad$ Eguiluz, Patxi. (2017). Tags: España, Arquitectos. 22 junio.

- $\quad$ Elliott, John H. (1982). Poder y sociedad en la España de los Austrias. Barcelona. Crítica.

- $\quad$ Escudero, María Eugenia. (2005). Arquitectura y urbanismo de las Cuatro Villas de la Costa en la Edad Moderna. Santander. Universidad de Cantabria.

- $\quad$ Escudero, María Eugenia. (2017). Paisajes urbanos. La imagen artística de las ciudades portuarias atlánticas (Siglos XVI-XXI). Santander. Universidad Internacional Menéndez Pelayo (UIMP). Seminario del 21 al 23 de Agosto.

- Hoyo Aparicio, Andrés. (2000). “Economía, Empresa y Empresarios en el Santander de 1900”, Manuel Suárez Cortina (coord.), Santander hace un siglo. Santander. Universidad de Cantabria. pp. 30-63.

- $\quad$ Febvre, Lucien. (1975), Combates por la historia. Barcelona. Ariel, $4^{\mathrm{a}}$ ed

- González, Pilar. (24 de junio de 2017). "El gran día del Centro Botín”. Santander: El Diario Montañés. Recuperado de:_https://www.Eldiariomontanes.es.

- Instituto Nacional de Estadística (INE), Censo de población de Santander 2016; Explotación Estadística. Padrón Municipal de Cantabria 2016.

- $\quad$ Lanza, Ramón. (2005). "Crecimiento demográfico y transición urbana: el caso de la ciudad de Santander, 17521930", IH25. pp. 117-160.

- $\quad$ La Plataforma Deba presenta un recurso contencioso contra la ubicación del Centro Botín. Junio 2. 2012.

- Lodos, Francisco. S.J. (1942). "Los orígenes de la Diócesis de Santander", en Miscelánea de Comillas, 1. pp. 395-439.

Navarro, Vicenç. (14 de julio de 2017). “El poder del banco de Santander en el mundo artístico”. Público. 
Recuperado de: https://www.publico.es.

- $\quad$ Ordeig Corsini, José María. y Valtierra de Luis, Carmen. "Santander. Desarrollo Urbano desde 1950”. Recuperado de: https://dadun.unav.edu $>$ bitstream $>$ Urb.

- $\quad$ Ortega y Gasset, José. (2014). Meditaciones del Quijote. Madrid. Alianza Editorial.

- O Ortega, José. (ed.) (1998). "Antes y después del 98: evolución económica y actitudes empresariales en Cantabria”. El siglo de los cambios. Cantabria 1898-1998. Santander. Caja Cantabria, pp. 13-55.

- $\quad$ Palacio Atard, Vicente. (1960). El comercio de Castilla y el puerto de Santander en el siglo XVIII. Madrid. C.S.I.C. - $\quad$ Pozas, María Jesús. (1973). La peste de fines del siglo XVI en Santander. Bilbao. Memoria de Licenciatura, Facultad de Filosofía y Letras - Sección de Historia - de la Universidad de Deusto.

- Pozas, María Jesús (1992). "Bilbao y Santander: Dos ciudades marítimas en los Diarios de Jovellanos", en Letras de Deusto. Bilbao. núm. 56, noviembre-diciembre. pp. 107-126.

- $\quad$ Pozas, María Jesús. (1999). La población de Santander en el siglo XVIII. Deusto-Bilbao. Tesis Doctoral, Facultad de Filosofía y Letras -Sección de Historia.

- $\quad$ Pozas, María Jesús. (2014). “El puerto de Santander y el comercio marítimo en el S.XVIII”, Fundación de Historia Moderna XIII Reunión Científica Sevilla, 4-6 de junio de 2014. Sevilla. Universidad de Sevilla, 2014, pp. 553-567.

- $\quad$ Pozas, María Jesús. (octubre de 2017): "Los jesuitas en Santander desde la fundación del colegio por Doña Magdalena de Ulloa hasta la expulsión por Carlos III”, en ASCAGEN. Revista de la Asociación Cántabra de Genealogía, núm. 18. Recuperado de: ,https://ascagen.es.

- $\quad$ Pulido, Natividad. (23 de junio de 2017). "Abre sus puertas el Centro Botín, nueva joya de Cantabria”, $A B C$. Recuperado de: https://www.abc.es.

- $\quad$ Rodríguez, Ramón. (1980). La reconstrucción urbana de Santander, 1941-1950. Santander. Centro de Estudios Montañeses.

- Rodríguez, Ramón. (1987). Arquitectura regionalista y de lo pintoresco en Santander 1900-1950. Santander. Ediciones de Librería Estudio, Santander.

- Sazatornil, Luis. (1996). Arquitectura y desarrollo urbano de Cantabria en el siglo XIX. Santander. Servicio de Publicaciones de la Universidad de Cantabria.

- S S Simón Cabarga, José. (1979). Santander. Biografía de una ciudad. Santander. Ediciones Estudio.

- $\quad$ Sudjic, Deyan. (2007). La arquitectura y el poder: Cómo los ricos y los poderosos dan forma a nuestro mundo. Barcelona. Ariel.

- $\quad$ Tribunal Supremo. (15 de noviembre de 2016). "El Supremo anula el Plan General de Ordenación Urbana de Santander-CGPJ-Noticias Judiciales”. Recuperado de: https://www.poderjudicial.es.

- VV. AA. (1985). Santander. El Puerto y su historia. Bicentenario del Consulado del Mar, 1785-1985. Santander. Junta del Puerto de Santander.

- Zubieta, Juan Carlos. (2015). Opiniones y reflexiones sobre a vida social, Santander, El Diario Montañés.

\section{Referencias de imágenes}

- $\quad$ Figura 1. Vista General de Santander. Grabado de Jorge Braun y Frans Hogenberg (1575). Fuente: https:// escenasdesantander.blogspot.com

- $\quad$ Figura 2. Plano de Santander por el canónigo suizo Pellegrino Zuyer hacia 1660 
- $\quad$ Fuente: Simón Cabarga, José. (1979). Santander. Biografía de una ciudad. Santander. Ediciones de Librería Estudio, p. 32.

- $\quad$ Figura 3. El muelle de Santander en 1794. Cuadro de Mariano Sánchez

- $\quad$ Fuente: https://www.sbhac.net

- $\quad$ Figura 4. El muelle de Santander en 1881.

- $\quad$ Fuente: https://escenasdesantander.blogspot.com

- $\quad$ Figura 5. Palacio de la Magdalena de Santander de estilo "inglés"

- Fuente: https://palaciomagdalena.com/es/historia/

- $\quad$ Figura 6. El incendio de Santander en 1941

- Fuente: https://www.bing.com/images/search?q=incendio+de+santander+de+1941

- $\quad$ Figura 7. Vistas del paisaje al sur de la bahía de Santander

- Fuente: https://elfarodeferia.wordpress.com/2016/10/12/bahia-de-santander/

- $\quad$ Figura 8. Edificio del Centro Botín formado por dos edificios en el centro del muelle sobre la bahía

- $\quad$ Fuente: https://www.hola.com/viajes/2017080797964/centro-botin-santander

1 Sobre el grabado de Jorge Braun, véase Manuel de Assas en la serie "España pintoresca" que publica el "Semanario Pintoresco Español" (1847), incluye el capítulo "Santander", y se ilustra con el grabado, recreación del original, con el texto latino en romance. Otra versión es la de Marcelino Menéndez Pelayo, Biblioteca Municipal de Santander Menéndez Pelayo [B.M.P.], Colección Pedraja, Doc. 941, Ms. 6. Varias versiones, autógrafas e inéditas, de don Marcelino Menéndez y Pelayo. (Dentro del volumen, aunque independiente de él hay dos hojas sueltas impresas, en las que se reproduce la Descripción de Santander/por/Jorge Braun/ Traducción de Menéndez Pelayo.

2 La bahía de Santander desde el grabado de Jorge Braun a la actualidad ha perdido un $50 \%$ de su extensión por los rellenos y la desecación de una parte de las marismas que han sido destinadas a pastos, a la ampliación del puerto, a la creación de áreas industriales, residenciales y de servicios.

3 La sede central del Banco de Santander se halla en el Paseo de Pereda $n^{\circ} 9$ frente a los jardines de Pereda que le separan del mar, es obra del arquitecto santanderino Javier González de Riancho (1881-1953) realizado en 1940, de estilo neoclásico, está formado por dos cuerpos diferentes unidos por un arco sobre la calle del Martillo que fue añadido a finales de los años cincuenta y permite que pasen tanto peatones como vehículos.

4 Sudjic Deyan, en su libro La arquitectura y el poder: Cómo los ricos y los poderosos dan forma a nuestro mundo, realiza una crítica sobre la arquitectura convertida en representación del poder y arma propagandística. Hace una reflexión crítica y polémica sobre las relaciones entre los arquitectos y los poderosos a lo largo del convulso siglo XX, uno de los más violentos de la Historia. Sin embargo, el arquitecto Patxi Eguiluz defiende la arquitectura postmoderna en este artículo, "El Centro Botín de Renzo Piano conquista Santander: El 23 de junio se inaugurará el primer edificio en España de Renzo Piano, el Centro Botín, que espera convertirse en un nuevo hito arquitectónico y cultural que sitúe a Santander en el mundo", Tags: España, Arquitectos, 2206-2017. 
5 Es interesante reflexionar sobre el papel de la prensa española respecto a la construcción del Centro Botín. Por otra parte el New York Times, uno de los diarios más influyentes de Estados Unidos y del mundo ha publicado una serie de artículos sobre Emilio Botín y la influencia política y mediática que tuvo en España, y su relación con el Centro Botín. 